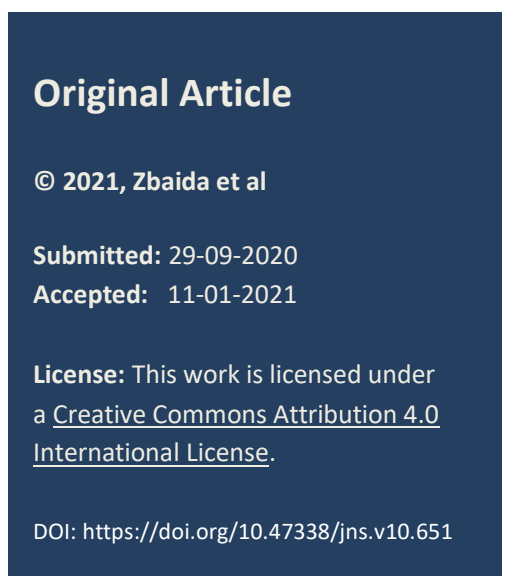

\title{
A comparison between primary endorectal pull-through and staged procedures for patients with Hirschsprung's disease
}

\author{
Reda Zbaida, ${ }^{*}$ Corné de Vos, Daniel Sidler
}

Department of Pediatric Surgery, Tygerberg Children's Hospital, Cape Town, South Africa

Correspondence*: Reda Zbaida, Department of Pediatric Surgery, Tygerberg Children's Hospital, Cape Town, South Africa E-mail: redazbida@yahoo.co.uk

\begin{abstract}
KEYWORDS
Hirschsprung's disease, Primary endorectal pullthrough,

Staged endorectal pullthrough

ABSTRACT

Background: Primary endorectal pull-through is becoming a standard of care across the globe. This study was done to compare the outcome of patients with Hirschsprung's disease (HD) who underwent primary endorectal pull-through with patients who were treated with a staged approach.

Methods: A retrospective data review was done of all patients diagnosed with Hirschsprung's disease (HD) at Tygerberg Children's Hospital, a tertiary hospital in Cape Town, during an 11-year period $(2007$ - 2018). The patients were divided into 2 groups: the primary Endorectal pull-through (ERP) group and the staged group and the two groups were compared.

Results: Eighty patients with histologically confirmed Hirschsprung's disease (HD) were seen at our institution during the study period $(2007-2018)$. Four patients did not meet the inclusion criteria and were excluded. Of the remaining seventy-six who were included, fortysix patients $(60.5 \%)$ had a primary endorectal-pull through (Primary group) and thirty patients $(39.5 \%)$ had staged procedures (Staged group) with a stoma before the final ERP. The peri-operative complications were subdivided into major and minor complications. Minor perioperative complications in the primary group were less $(13 \%)$ compared to the staged group (33\%) with a p-value of 0.017 , making the difference statistically significant. Anastomotic strictures were the most common complication in both groups with abdominal wound infection being more common in the staged group. The late complications were similar in both groups with a p-value of 0.43. Constipation was the most common complication in both groups, followed by soiling.

Conclusion: The two groups had a similar outcome without statistically significant differences. We can safely conclude that the primary endorectal pull-through for HD is at least as safe as the staged approach in Sub- Saharan Africa. With this technique, we avoid a stoma and the necessity for two surgical procedures with added potential complications.
\end{abstract}

\section{INTRODUCTION}

Hirschsprung's disease (HD) is a congenital condition characterized by the absence of ganglion cells in the submucosal (Meissner's) and myenteric plexus of the distal bowel. [1,2] It is more common in males $(\mathrm{M}: \mathrm{F}=3.2: 1)$ and is the most common cause of distal bowel obstruction in both neonates and older children.[1,3]

HD can be classified as short-segment (recto-sigmoid) and long-segment HD. Long segment HD can be further subdivided into long segment colonic aganglionosis, total colonic aganglionosis, and small bowel aganglionosis.[4] Various surgical methods have been described over the years for definitive surgery, with endorectal pull-through (ERP) being the latest addition. De la Torre-Mondragon and J.A. Ortega -Salgado first described this method in 1998, which has since become the most popular surgery for short segment Hirschsprung's disease worldwide.[1,5,6] ERP is a minimally invasive technique, executed meticulously with good results. Both single and multicentric studies have shown it to be safe, easy to master, without potential risks of complications related to the laparotomy and stoma.[7-9] 
New studies are being published with favorable short and long-term outcomes in patients undergoing this procedure.[10-13] To the best of our knowledge, this is the first review assessing the short and long-term outcomes of primary endorectal pull-through in SubSaharan Africa. Primary ERP for short segment HD was introduced in our unit in 2007 and is currently the preferred elective procedure for short segment Hirschsprung's disease.

\section{METHODS}

A retrospective data review was done of all patients diagnosed with Hirschsprung's disease (HD) at Tygerberg Children's Hospital, a tertiary care hospital, during an 11-year period (2007 - 2018). The patients were divided into two groups: the primary Endorectal pull-through (Primary) group and the staged (Staged) group.

Patient's medical records, operation theatre notes, discharge summaries, and patient questionnaires (completed by part of the surgical team) were used in the data collection. The age of the patient at the time of diagnosis and surgery, gender, type of surgery, length of hospital stay, perioperative complications (including intraoperative to six months post-surgery), and late complications (from six months post definitive surgery) were included in the data collection.

Also, late outcomes and complications were assessed by completion of an age-appropriate questionnaire for caregivers of children older than two years.[14] The questionnaire is based on the Krickenbeck classification system, which is currently one of the most used systems to assess bowel function in HD patients.

Patients with histological confirmation of the disease, those that signed consent, and those that had their definitive ERP done in our unit were included in the study. The exclusion criteria were pre-operative mortality, the definitive surgery done in another unit, and repeated complex surgery. Ethical approval was obtained from the HREC (S20/06/149).

The diagnosis of HD was confirmed on histology with either a rectal suction biopsy or a full-thickness rectal biopsy. A contrast enema was performed in all patients, to assess the level/length of diseased bowel and to assist with surgical planning.

The primary group included patients who had an ERP as the first surgery without a stoma. Patients that had a laparoscopically assisted or laparotomy assisted pull-through, as first surgery, were also included.

All patients who had a stoma first and then an ERP later with/or without laparoscopy or laparotomy were included in the staged group. The decision to fashion a stoma for patients mostly depended on his/her response to rectal washouts as well as the preference of the surgeon in the most recent cases.
Data was tabulated on an excel spreadsheet for quantitative assessments. The P-value was calculated using the t-test for 2 independent means and a value of $<0.05$ was considered statistically significant.

\section{RESULTS}

Eighty patients with histologically confirmed Hirschsprung's disease (HD) were treated in our institution during the study period $(2007-2018)$. Four patients did not meet the inclusion criteria and were excluded. Of those four, one was operated in another center, one died before definitive surgery and two were complicated cases and were excluded due to the repeated histological diagnosis being inconclusive leading to multiple complex surgeries. Of the remaining 76 who were included, forty-six patients $(60.5 \%)$ had a primary endorectal-pull through (Primary) and 30 patients $(39.5 \%)$ had staged procedures (Staged) with a stoma before the final ERP.

Thirty-five out of the 46 patients included in the primary group were males. The median age at surgery (ERP) was 6 weeks (2-364 weeks) and the mean hospital stays post-operatively was 5.5 days. Nineteen of the 46 patients $(41 \%)$ had their ERP during the neonatal period.

In comparison, the staged group had 22 males and 8 females (Table 1). The median age of definitive ERP in the staged group was 40 weeks $(15-520$ weeks) with 20 of these patients being operated on between 1 and 12 months of age and a mean hospital stay post-ERP of 5.3 days. Although the mean hospital stay postERP was slightly less in the staged group, the extra days post-stoma was not added and in total this number would have been much higher making the total hospital stay longer in the staged group.

Table 1: Comparison between the Primary and Staged Group

\begin{tabular}{|c|c|c|}
\hline & $\begin{array}{l}\text { Primary } \\
\text { Group }\end{array}$ & $\begin{array}{l}\text { Staged } \\
\text { Group }\end{array}$ \\
\hline Total number & 46 & 30 \\
\hline Male: Female & $35: 11$ & $22: 8$ \\
\hline Median age at surgery (weeks) & 6 & 40 \\
\hline $\begin{array}{l}\text { Mean hospital stay post definitive } \\
\text { surgery }\end{array}$ & 5.5 days & 5.3 days \\
\hline $\begin{array}{cc}\text { Type of HD if documented: } \\
\bullet \quad \text { Short segment } \\
\bullet \quad \text { Long segment } \\
\bullet \quad \text { Not documented }\end{array}$ & $\begin{array}{l}34 \\
5 \\
7 \\
\end{array}$ & $\begin{array}{l}21 \\
9 \\
0 \\
\end{array}$ \\
\hline Patients with a family history of HD & 2 & 2 \\
\hline
\end{tabular}

We had 5 premature babies who were diagnosed with HD during the neonatal period, the youngest at a gestational age of 32 weeks. An interesting finding was that 4 out of the 5 were female and 1 of them was also diagnosed with Trisomy 21. Three of these babies had their primary ERP done during the neonatal period. The other 2 had stomas done after 
28 days of age and an ERP during infancy. No complications were encountered in this sub-group of patients.

The overall rate of perioperative complications in the primary group was lower $(24 \%)$ compared to the staged group (40\%). We included all intraoperative complications up to 6 months post-ERP in this group of complications and sub-divided them into minor complications (needed non-operative treatment) and major complications (needed major surgery). The primary group had $6(13 \%)$ minor peri-complications compared to $10(33 \%)$ in the staged group (Table 2). With a p-value of 0.017 , this difference was statistically significant. Anastomotic strictures were the most common complication in the primary group, while anastomotic strictures and abdominal wound infection being the most common in the staged group. The patients with anastomotic strictures were started on to anal dilatations and all patients in the staged group responded, while 1 case in the primary group eventually required myomectomy.

Table 2: Minor Perioperative complications

\begin{tabular}{|l|l|l|l|}
\hline Complication & $\begin{array}{l}\text { Primary } \\
\text { Group } \\
(\mathbf{N}: \mathbf{4 6})\end{array}$ & $\begin{array}{l}\text { Staged } \\
\text { Group } \\
(\mathbf{N}: \mathbf{3 0})\end{array}$ & p-value \\
\hline $\begin{array}{l}\text { Colorectal anastomotic } \\
\text { breakdown: }\end{array}$ & 2 & 2 & \\
\hline $\begin{array}{l}\text { Minor (treated with } \\
\text { local procedures and } \\
\text { antibiotics only) }\end{array}$ & 2 & 3 & \\
\hline $\begin{array}{l}\text { Abdominal wound infection } \\
\text { ERP and stoma closure } \\
\text { done at the same time) }\end{array}$ & 0 & 2 & $\mathbf{P}=\mathbf{0 . 0 1 7}$ \\
\hline $\begin{array}{l}\text { Abdominal wound } \\
\text { dehiscence }\end{array}$ & 0 & $\mathbf{6}$ & $\mathbf{1 0}(\mathbf{3 3} \%)$ \\
\hline Anastomotic stricture & $\mathbf{6} \%)$ & \\
\hline TOTAL & & & \\
\hline
\end{tabular}

Table 3: Major Perioperative complications

\begin{tabular}{|c|c|c|c|}
\hline Complication & $\begin{array}{l}\text { Primary } \\
\text { Group } \\
(N: 46)\end{array}$ & $\begin{array}{l}\text { Staged } \\
\text { Group } \\
(N: 30)\end{array}$ & $p$-value \\
\hline \multicolumn{4}{|l|}{$\begin{array}{l}\text { Colorectal anastomotic } \\
\text { breakdown: }\end{array}$} \\
\hline $\begin{array}{l}\text { - } \quad \text { Major (requiring relook } \\
\text { laparotomy and stoma) }\end{array}$ & 2 & 1 & \\
\hline Adhesive bowel obstruction & 2 & 0 & \\
\hline Twisted distal bowel & 1 & 0 & \\
\hline Ureteric injury & 0 & 1 & \\
\hline TOTAL: & 5 & 2 & $P=0.27$ \\
\hline
\end{tabular}

The major perioperative complications between the two groups (Table 3) were not statistically significant $(p$-value $=0.27)$. We had one case in the primary group where the distal bowel was twisted during the ERP. This patient developed bowel obstruction and required a relook laparotomy with a colostomy to relieve the obstruction. The Duhamel procedure was done for him at a later stage.

When we looked at the perioperative complications in the different age groups, we found that most of the major complications $(80 \%)$ in the primary group occurred in infancy (Fig 1). In comparison most of the minor complications in the staged group presented in patients that had their ERP after 1 year of age while the major complications were the same for both the infant group and late presenters.

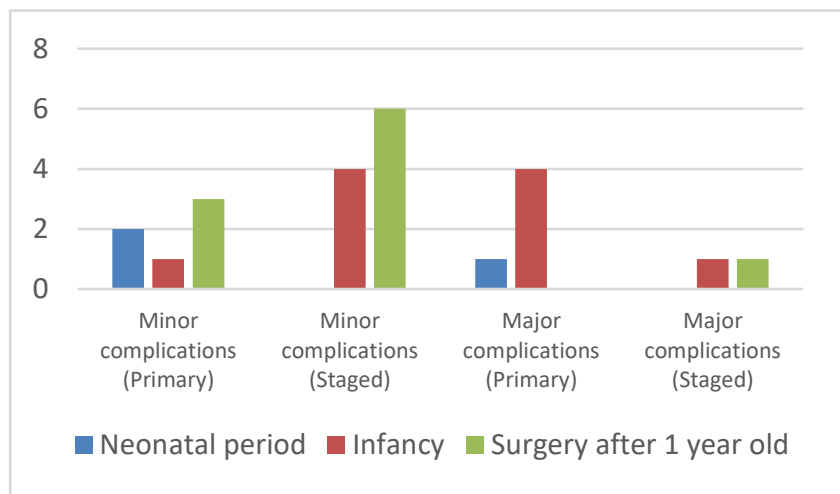

Fig 1: Age-group related perioperative complications

The age-appropriate follow-up questionnaires were completed by 22 caregivers of patients in the primary group (48\%) and $15(50 \%)$ in the staged group (Table 4). The average age of follow-up and completion of the questionnaire was 6 years for both groups. Only one child in the primary group complained about soiling (Gr 3 that was later treated with an ACE) and 10 children had constipation ( 8 were of Grade 2 and were treated with laxatives). In comparison, two patients in the staged group complained about soiling at the time of follow-up while 5 complained about constipation (managed with regular laxatives).

Table 4: Main results from the follow-up questionnaire

\begin{tabular}{|c|c|c|c|}
\hline & & $\begin{array}{l}\text { Primary } \\
22 / 46 \\
(48 \%)\end{array}$ & $\begin{array}{l}\text { Staged } \\
15 / 30 \\
(50 \%)\end{array}$ \\
\hline 1 & Voluntary bowel movement & 21 & 13 \\
\hline 2 & $\begin{array}{l}\text { Soiling: } \\
\text { Grade 1: Once or twice per week } \\
\text { Grade 2: Everyday, no social } \\
\text { problems } \\
\text { Grade 3: Constant, social } \\
\text { problems (e.g., Nappies) }\end{array}$ & $\begin{array}{l}1 \\
0 \\
0 \\
1\end{array}$ & $\begin{array}{l}2 \\
0 \\
1 \\
1\end{array}$ \\
\hline 3 & $\begin{array}{l}\text { Constipation: } \\
\text { Grade 1: Diet changes only } \\
\text { Grade 2: Regular laxatives } \\
\text { Grade 3: Daily bowel washouts }\end{array}$ & $\begin{array}{l}10 \\
1 \\
8 \\
1\end{array}$ & $\begin{array}{l}5 \\
0 \\
4 \\
1\end{array}$ \\
\hline
\end{tabular}

The late complications were similar in both groups (Table 5). Constipation was the most common complication in both groups, followed by soiling. One patient in the primary group presented with severe 
soiling and required an Antegrade Continence Enema (ACE) to keep him clean. Both the patients in the staged group responded to conservative management (laxatives and bowel washouts) and symptoms improved gradually over 2 years.

One patient from the staged group was diagnosed with a hyper-motile colon (diagnosed with manometry and exclusion of other causes) and was treated empirically with Loperamide and Clonidine. The patient responded to treatment and is doing well on follow-up.

Table 5: Late complications

\begin{tabular}{|l|c|c|c|}
\hline \multicolumn{1}{|c|}{ Complications } & $\begin{array}{c}\text { Primary } \\
(\mathbf{N}: \mathbf{4 6})\end{array}$ & $\begin{array}{c}\text { Staged } \\
(\mathbf{N}: \mathbf{3 0})\end{array}$ & $\begin{array}{c}\text { p-value } \\
\text { (Total } \\
\text { only) }\end{array}$ \\
\hline Constipation & 10 & 5 & \\
\hline Soiling & 1 & 2 & \\
\hline $\begin{array}{l}\text { Anastomotic } \\
\text { stricture }\end{array}$ & 1 & 0 & \\
\hline $\begin{array}{l}\text { Hyper-motile colon } \\
\text { Perianal abscess }\end{array}$ & 0 & 1 & \\
\hline Mortality & 0 & 1 & $\mathbf{P}=\mathbf{0 . 4 3}$ \\
\hline TOTAL & $\mathbf{1 2 ( 2 6 \% )}$ & $\mathbf{1 0 ~ ( 3 3 \% )}$ & \\
\hline
\end{tabular}

Hirschsprung's related enterocolitis (HREC) were encountered in both groups but were excluded from both peri-operative and late complications as we did not consider this a surgery-related complication, but rather a complication related to the nature of the disease.

We had three mortalities in the cohort. Two were in the staged group and one was in the primary group. Two deaths were not surgery-related (1 patient demised secondary to pneumonia and the second from pneumonia and missed enterocolitis). The only one surgery-related mortality was in the staged group where the patient died secondary to sepsis from an anastomotic breakdown post stoma closure.

One of the 46 patients in the primary group had a covering stoma due to difficult surgery and this was closed 3 months later without any complication. A further six patients required stomas after the definitive surgery, 2 from the staged group, and 4 from the primary group (already mentioned in the complications above). The reasons for stomas postdefinitive surgery included a stricture in the transverse colon in a patient that was later diagnosed with skip lesions, 1 patient with a complicated perianal fistula not improving with conservative treatment, 2 patients with an anastomotic breakdown, 1 twisted pull-through, and 1 patient with repeated episodes of severe enterocolitis.

\section{DISCUSSION}

Bowel obstruction in infancy is often due to Hirschsprung's disease (HD).[15] Histology is the gold standard for diagnosis. A contrast enema, showing the level of the diseased bowel, is essential to assist the diagnosis and also for surgical planning.[15]

In 2007 we started with primary ERP as a surgical option for HD patients in our unit. Recently, there is a surge in publications about the outcome of primary ERPs from developing countries. Al-Baghaday et al from Egypt reviewed 84 patients and reported a zeroconversion rate, no intraoperative complications, and no significant early complications.[7] Ghorbanpour et al., from Iran, reviewed 55 patients and reported intestinal obstruction $(25.5 \%)$ and constipation $(27.3 \%)$ as the most common early and late complications, respectively.[16]

Anastomotic strictures account for the most common cause of mechanical obstruction after ERP.[17] The symptoms of obstruction may present as abdominal distension, bloating, borborygmi, vomiting, or severe constipation.[18] Anastomotic strictures are diagnosed on digital rectal examination. Pratap et al. claimed that a "flimsy synechiae" (early fibrosis) can be present as early as 7 days post-surgery. They recommend starting daily anal dilatation on day 7 post-operatively and continuing up to 3 months postoperatively to reduce the rate of anal stricture.[19] In comparison, Rouzrokh et al recommend starting anal dilatation after 2 weeks post-operatively. They claimed that starting earlier dilatation may cause damage to the anastomotic site.[20] In our unit, we bring the patients back for either an EUA in theater or a rectal examination in the clinic (depending on the age of the patient and the primary surgeon) two weeks post ERP. We only start dilatations if a stricture is present at that time.

El-sawaf et al. also compared primary ERP with a staged procedure. They found anastomotic strictures to be more common in the staged group (26.6\%) compared to the primary group (15.4\%).[21] The reason for this may be that two surgical procedures increase the risk of compromised blood supply and subsequently leads to strictures at the anastomotic site.[11] One way to avoid this might be by using bipolar diathermy for the dissection instead of monopolar diathermy to decrease the chances of injury to the blood supply. In our cohort, 10\% (3 cases) of patients in our staged group developed anastomotic strictures as a perioperative complication compared to $8.7 \%$ (4 cases) in the primary group. The difference between the two groups was statistically insignificant. Worth mentioning is that all the patients in our series who developed anastomotic strictures postoperatively were male. 
This finding correlates with a recent study from Neuvonen et al. who describes being male as one of the indicators for a worse surgical outcome.[22]

Romero et al. in 2001 studied that partial anastomotic dehiscence (not complete dehiscence) post-ERP were more common in their staged group $(n=29)$ compared to primary-ERP $(n=24)$. They had 4 anastomotic leaks in their primary group (16.7\%) and 5 in their staged group (17.2\%). One patient from each group complicated with abscess formation at the site of the leakage (which required reoperation) and the rest healed uneventfully after re-suturing.[23] In another multicenter comparative study, Kim et al. reported an anastomotic leak rate of $1 \%$ in patients who underwent a staged approach.[24] In contrast, Teitelbaum et al. reported a higher rate of anastomotic leakage (it is not specified if it was partial or complete) in their staged group (9.7\% compared to the $2.6 \%$ in their primary group).[11] The rate of colorectal anastomotic leaks in our cohort is higher in the staged group (10\%) compared to the primary group (8.6\%). We do accept that the statistical significance of this difference is limited may be due to the small sample size.

Stensrud et al. reported no adhesive intestinal obstruction in cases who underwent primary endorectal approach and $4 \%$ in those with laparotomy assisted approaches.[25] Torre-Mondragon et al. in 2000 reported only 1 case in their staged group (10\%) that developed adhesive bowel obstruction and nil in patients who underwent endorectal or laparotomy assisted pull-through.[26] We had 2 cases of adhesive intestinal obstruction, both in the Primary group. The most common causes of obstructive symptoms after pull-through include mechanical obstruction, persistent or acquired aganglionosis, internal sphincter achalasia, motility disorders, and functional megacolon (stool-holding behavior).[7,17] The main aim of the workup for patients with postoperative obstruction is to exclude any mechanical causes.[17]

Pratap et al. reported a peri-anal abscess rate of $3.07 \%$ in their retrospective review. The reasons for peri-anal abscesses post-pull-through included damage to the mucosal tube, retraction of anastomosis, and/or poor blood supply due to massive dissection.[19]

The constipation rate after surgical repair of Hirschsprung's disease varies significantly in the literature, ranging from $0 \%-25 \%$ in the primary group and $4.76 \%-27.6 \%$ in the staged group.[2,23,24,25,27] Bjornland et al. reported 25\% constipation rate in their multicenter study.[28] This confirms that constipation is a common and longstanding complication even after a properly performed surgical procedure. The constipation rate in our cohort was $21.7 \%$ in the primary group and $16.7 \%$ in the staged group.

Stool-holding behavior (functional megacolon) is responsible for up to half of constipation cases in normal children. It is suspected to be more common in Hirschsprung's patients because of their susceptibility to developing constipation. $[7,17]$ It is a known fact that Hirschsprung disease patients do not have a normal recto-anal inhibitory reflex. For unknown reasons, some patients restore the reflex after surgical repair, but most patients wouldn't be able to restore this reflex.[29] Loss of this reflex contributes to persistent internal sphincter spasm (Achalasia).[30] This shows that the pathology in Hirschsprung disease is not localized to the aganglionic segment. Local applications of Nitroglycerin paste, injections of botulinum toxin, and internal sphincter myectomy have been suggested for the management of internal sphincter achalasia.[18] Motility disorder of proximal bowel may also play role in some patients presenting with constipation postoperatively. Abnormalities in the ganglion cells in the proximal bowel are responsible for hypoperistalsis. These abnormalities could be in the number of ganglion cells, the size, or the distribution thereof.[31] Meinds et al. emphasized another reason that could contribute to constipation after resection of the aganglionic segment which is a pelvic floor dyssynergia that leads to paradoxical external sphincter contractions.[32] Treatment of this condition includes a high fiber diet, hydration, toilet training, and pelvic floor muscles exercises.[30]

The literature review suggests the rate of soiling ranging from $4.8 \%-29.2 \%$ for primary ERP and 9.5\%$41.4 \%$ the staged surgery.[2,33,34] In our cohort, 3 patients had soiling: 1 in the Primary group $(2.17 \%)$ and 2 in the Staged Group (6.67\%). A big concern in the literature seems to be the long-term effects of over-stretching of the sphincter mechanism while doing a primary ERP.[35] A multicenter Nordic study, looking at the long-term outcome of the endorectal pull-through, showed that it has a legitimate concern.[28] The soiling due to damage of the anal canal is a "preventable, irreparable, and irreversible complication".[36] To avoid such a devastating complication, Torre-Mondragon et al. recommended that one should protect the entire anal canal and start the incision $2 \mathrm{~cm}$ above the dentate zone to preserve the highly sensitive area, which is essential for fecal continence.[36] They further recommended dilating the anus before placement of the lone star retractor ${ }^{\circledR}$ with a Hagar dilator up to 2 numbers higher than the number that corresponds to the age of the patient, to relax the sphincter muscle.[36] Applying traction sutures on the proximal end of the mucosa further helps dissection without aggressive 
retraction on the sphincter mechanism.[15] In a review of fecal incontinence after surgical repair of Hirschsprung's disease in 2017, Bischoff et al. concluded that a meticulous surgical technique may further avoid this complication.[37]

Soiling after surgical repair for HD can be categorized into the hyper-motile colon and hypo-motile colon. Radiology (plain abdominal X-rays and contrast enema) can help to differentiate between these two conditions. The hypo-motile colon has fecal loading (X-ray) and increased diameter of the colon, while no fecal loading and a normal or decreased diameter of the colon will be seen in the hyper-motile colon. In the hyper-motile group, multiple factors play a role in its pathophysiology which includes persistent or noncoordinated contractions.[38,39] Furthermore, these patients have a loss of their sigmoid colon which has 2 roles in the continence, the first being a reservoir for stool and the second that it does not respond to high amplitude propagated contractions (HAPCs) which have an essential role to move the stool from the right side to the left side of the colon. Resection of the sigmoid colon results in the loss of these protective mechanisms. The dissection during surgery may also affect the anorectal angle of the puborectalis muscle which helps in the continence leading to postoperative soiling.[40]

In our cohort, 1 patient was diagnosed with a hypermotile colon postoperatively. Abdominal X-ray did not show fecal loading, and contrast enema showed a normal caliber colon and the examination under general anesthesia was normal. This patient was treated empirically with Loperamide and Clonidine and responded well.

In our experience, patients presenting in the neonatal period respond well to rectal washouts and are more suitable for a primary-ERP. It correlates with the finding of $\mathrm{Lu}$ et al.[41] In addition, the safety of a primary pull-through in the neonatal period has been

\section{REFERENCES}

1. Moore SW. Hirschsprung disease: current perspectives. Open Access Surg. 2016; 9:39-50. Available from: https://doi.org/10.2147/OAS.S81552.

2. Aslanabadi S, Ghaleh Golab-Behbahan A, Zarrintan S, Jamshidi M, Seyed Hejazi M. Transanal one-stage endorectal pull-through for Hirschsprung's disease: a comparison with the staged procedures. Pediatr Surg Int. 2008; 24:925.

3. Wester T, Granström AL. Hirschsprung disease-Bowel function beyond childhood. Semin Pediatr Surg. [Internet]. 2017; 26:322-7. Available from: https://doi.org/10.1053/j.sempedsurg.2017.09.008.

4. Moore SW. Total colonic aganglionosis in Hirschsprung disease. Semin Pediatr Surg. [Internet]. 2012; 21:302-9. well documented in the literature.[11,42] Rectal washouts alone for decompression of the bowel seems less successful in late presenters, as documented by Ekenze et al. from Nigeria who showed a failure rate (of rectal washouts to adequately decompress the bowel) of more than $80 \%$ in their patients older 1 year and eventually needing a colostomy for effective decompression.[43] It correlates with Stensrud et al. and our experience.[44]

Small sample size and inherent bias in a retrospective study cannot be eliminated. We also acknowledge that we have a small sample size. Bigger, multi-centric studies are proposed to eliminate bias and explore the ideal age for primary vs staged procedures. It is important to highlight that $33.3 \%$ of the staged group had stoma-related complications including prolapse and a leaking Hartman's pouch which required another laparotomy. This should be taken into consideration when looking at the overall results.

\section{CONCLUSION}

The two groups had a similar outcome without significant statistical differences. We can safely conclude that the primary endorectal pull-through for HD is at least as safe as the staged approach in SubSaharan Africa. We recommend a primary endorectal pull-through for HD in the neonatal period, as they respond better to rectal washouts. A primary ERP avoids stomas and their added (often-severe) complications, as well as the additional burden of two surgical procedures. A careful patient selection should be done for ERP. In our experience, infants (patients between 1-12 months of age) should undergo a staged approach, as primary ERP in them has higher complication rates.

Acknowledgements: $\mathrm{Nil}$

Conflict of Interest: Authors have no conflict of interest.

Source of Support: Nil

Consent to Publication: No clinical figure is used in this manuscript.

Author Contributions: Author(s) declared to fulfil authorship criteria as devised by ICMJE and approved the final version.

Available from: https://doi.org/10.1053/j.sempedsurg. 2012.07.004.

5. De La Torre-Mondragón L, Ortega-Salgado JA. Transanal endorectal pull-through for Hirschsprung's disease. J Pediatr Surg. [Internet]. 1998 [cited 2017 Apr 29]; 33:1283-6. Available from: http://ac.elscdn.com.ez.sun.ac.za/S0022346898901695/1-s2.0S0022346898901695-main.pdf?_tid=e58c83ae-2cd7$11 \mathrm{e} 7-8606-00000$ aacb35f\&acdnat $=1493469324_{\text {_ }}$ 228f20ebca53a8098a335ea3c7884b18.

6. Gunadi, Karina SM, Dwi Hantoro A. Outcomes in patients with Hirschsprung disease following definitive surgery. BMC Res Notes. [Internet]. 2018; 11:1-5. Available from: https://doi.org/10.1186/s13104-018- 
3751-5.

7. Al-Baghdady AA, El-Shafei EA, El-Asmar KM. One-stage transanal Swenson procedure for rectosigmoid Hirschsprung's disease in infants and children. Ann Pediatr Surg. 2016; 12:104-8.

8. Onishi S, Nakame K, Yamada K, Yamada W, Kawano T, Mukai M, et al. Long-term outcome of bowel function for 110 consecutive cases of Hirschsprung's disease: Comparison of the abdominal approach with transanal approach more than 30 years in a single institution - is the transanal approach truly beneficial for bowel function. J Pediatr Surg. [Internet]. 2016; 51:2010-4. Available from: https://doi.org/10.1016/j.jpedsurg. 2016.09.029.

9. Ruttenstock E, Puri P. Systematic review and metaanalysis of enterocolitis after one-stage transanal pullthrough procedure for Hirschsprung's disease. Pediatr Surg Int. 2010; 1101-5.

10. Martínez-Criado Y, Cabrera R, Moya MJ, Valladares JC, López-Alonso M, De Agustín Asensio JC. Results of transanal endorectal descent in Hirschprung's disease. Cirugía Española. 2015; 93:561-6.

11. Teitelbaum DH, Cilley RE, Sherman NJ, Bliss D, Uitvlugt ND, Renaud EJ, et al. A decade of experience with the primary pull-through for Hirschsprung disease in the newborn period: A multicenter analysis of outcomes. Ann Surg. 2000; 232:372-80.

12. $\mathrm{Mk} \mathrm{S}$, Sherchan M, Bg D, Rb B. Early experience with single-stage transanal endorectal. J Nepal Paediatr Soc. 2014; 34:188-94.

13. Zimmer J, Tomuschat C, Puri P. Long-term results of transanal pull-through for Hirschsprung's disease: a meta-analysis. Pediatr Surg Int. [Internet]. 2016 [cited 2018 Apr 2]; 32:743-9. Available from: http://link.springer.com/10.1007/s00383-016-3908-z.

14. To W, Toilet B, Child Y, Started G. Toilet training guidelines: Parents-the role of the parents in toilet training. Pediatr. [Internet]. 1999; 103:1362-3. Available from: http://www.ncbi.nlm.nih.gov/ pubmed/10353955.

15. De La Torre L, Langer JC. Transanal endorectal pullthrough for Hirschsprung disease: technique, controversies, pearls, pitfalls, and an organized approach to the management of postoperative obstructive symptoms. Semin Pediatr Surg. [Internet]. 2010; 19:96-106. Available from: https://doi.org / 10.1053/j.sempedsurg.2009.11.016.

16. Ghorbanpour M, Seyfrabie MA, Yousefi B. Early and long-term complications following transanal pull through Soave technique in infants with Hirschsprung's disease. Med Pharm Rep.2019; 92:382-6.

17. Avansino JR, Levitt MA. Hirschsprung disease [Internet]. 7th ed. Fundamentals of Pediatric Surgery, Second Edition. Elsevier Inc.; 2016. 513-524 p. Available from: https://doi.org/10.1016/B978-0-32307255-7.00101-X.

18. Langer JC, Rollins MD, Levitt M, Gosain A, de la Torre L, Kapur RP, et al. Guidelines for the management of postoperative obstructive symptoms in children with Hirschsprung disease. Pediatr Surg Int. 2017; 33:5236.

19. Pratap A, Gupta DK, Shakya VC, Adhikary S, Tiwari A, Shrestha $\mathrm{P}$, et al. Analysis of problems, complications, avoidance and management with transanal pull- through for Hirschsprung disease. J Pediatr Surg. 2007; 42:1869-76.

20. Rouzrokh M, Khaleghnejad AT, Mohajerzadeh L, Heydari A, Molaei $H$. What is the most common complication after one-stage transanal pull-through in infants with Hirschsprung's disease? Pediatr Surg Int. 2010; 26:967-70.

21. El-sawaf MI, Drongowski RA, Chamberlain JN, Coran AG, Teitelbaum DH. Are the long-term results of the transanal pull-through equal to those of the transabdominal pull-through? A comparison of the 2 approaches for Hirschsprung disease. J Pediatr Surg. 2007; 42:41-7.

22. Neuvonen MI, Kyrklund K, Lindahl HG, Koivusalo AI, Rintala RJ, Pakarinen MP. A population-based, complete follow-up of 146 consecutive patients after transanal mucosectomy for Hirschsprung disease. $\mathrm{J}$ Pediatr Surg. [Internet]. 2015; 50:1653-8. Available from: https://doi.org/10.1016/j.jpedsurg.2015.02.006.

23. Romero P, Kroiss M, Chmelnik M, Königs I, Wessel LM, Holland-Cunz S. Outcome of transanal endorectal vs. transabdominal pull-through in patients with Hirschsprung's disease. Langenbecks Arch Surg. [Internet]. 2011 [cited 2018 Oct 17]; 396:1027-33. Available from: http://link.springer.com/10.1007/ s00423-011-0804-9.

24. Kim AC, Langer JC, Pastor AC, Zhang L, Sloots CEJ, Hamilton NA, et al. Endorectal pull-through for Hirschsprung's disease-a multicenter, long-term comparison of results: transanal vs transabdominal approach. J Pediatr Surg. [Internet]. 2010 [cited 2018 Mar 6]; 45:1213-20. Available from: https://wwwclinicalkey-com.ez.sun.ac.za/\#!/content/journal/1s2.0-S002234681000206X.

25. Stensrud KJ, Emblem R, Bjørnland K. Functional outcome after operation for Hirschsprung diseasetransanal vs transabdominal approach. J Pediatr Surg. [Internet]. 2010; 45:1640-4. Available from: https://doi.org/10.1016/j.jpedsurg.2010.02.065.

26. De la Torre L, Ortega A. Transanal versus open endorectal pull-through for Hirschsprung's disease. J Pediatr Surg. 2000; 35:1630-2.

27. Fitzgerald PG, Winthrop AL, Skinner MA, Ternberg JL, Lau GYP, Foglia P. One-stage versus two-stage Soave pull-through for Hirschsprung's Disease in the first year of life. J Pediatr Surg. 1996; 31:33-7.

28. Bjørnland K, Pakarinen MP, Stenstrøm P, Stensrud KJ, Neuvonen M, Granström AL, et al. A Nordic multicenter survey of long-term bowel function after transanal endorectal pull-through in 200 patients with rectosigmoid Hirschsprung disease. J Pediatr Surg. [Internet]. 2017; 52:1458-64. Available from: https://doi.org/10.1016/j.jpedsurg.2017.01.001.

29. Chung PHY, Wong KKY, Leung JL, Tam PKH, Chung KLY, Leung MWY, et al. Clinical and manometric evaluations of anorectal function in patients after transanal endorectal pull-through operation for Hirschsprung's disease: A multicentre study. Surg Pract. 2015; 19:113-9.

30. Ladi-seyedian S, Shari L, Manouchehri N, Ashjaei B. A comparative study of transcutaneous interferential electrical stimulation plus behavioral therapy and behavioral therapy alone on constipation in postoperative Hirschsprung disease children. J Pediatr 
Surg. 2017; 52:177-83.

31. Puri P, Gosemann JH. Variants of Hirschsprung disease. Semin Pediatr Surg. [Internet]. 2012; 21:310-8. Available from: https://doi.org/10.1053/j.sempedsurg. 2012.07.005.

32. Meinds RJ, Eggink MC, Heineman E, Broens PMA. Dyssynergic defecation may play an important role in postoperative Hirschsprung's disease patients with severe persistent constipation: Analysis of a case series. J Pediatr Surg. [Internet]. 2014; 49:1488-92. Available from: https://doi.org/10.1016/j.jpedsurg.2014.05.001.

33. Gunnarsdóttir A, Larsson LT, Arnbjörnsson E. Transanal endorectal vs. Duhamel pull-through for Hirschsprung's disease. Eur J Pediatr Surg. 2010; 20:242-6.

34. Tannuri ACA, Tannuri U, Romão RLP. Transanal endorectal pull-through in children with Hirschsprung's disease-technical refinements and comparison of results with the Duhamel procedure. J Pediatr Surg. [Internet]. 2009; 44:767-72. Available from: https://doi.org/10.1016/j.jpedsurg.2008.08.002.

35. van Leeuwen K, Geiger JD, Barnett JL, Coran AG, Teitelbaum DH. Stooling and manometric findings after primary pull-throughs in Hirschsprung's disease: Perineal versus abdominal approaches. J Pediatr Surg. [Internet]. 2002 [cited 2018 Oct 17]; 37:1321-5. Available from: https://www.sciencedirect.com/ science/article/pii/S0022346802000878.

36. De L, Cogley K, Santos K, Morales O, Calisto J. The anal canal is the fine line between "fecal incontinence and colitis" after a pull-through for Hirschsprung disease. J Pediatr Surg. [Internet]. 2017; 52:2011-7. Available from: https://doi.org/10.1016/j.jpedsurg. 2017.08.040.

37. Bischoff A, Frischer J, Leslie J, Dickie B, Levitt MA, Holder M, et al. Damaged anal canal as a cause of fecal incontinence after surgical repair for Hirschsprung disease - a preventable and under-reported complication. J Pediatr Surg. 2017; 52:549-53. Available from: https://doi.org/10.1016/j.jpedsurg. 2016.08.027.

38. Levitt MA, Martin CA, Olesevich M, Bauer CL, Jackson LE, Peña A. Hirschsprung disease and fecal incontinence : diagnostic and management strategies. J Pediatr Surg. 2009; 44:271-7. Available from: https://doi.org/10.1016/j.jpedsurg.2008.10.053.

39. Hyman PE. Defecation disorders after surgery for Hirschsprung's disease. J Pediatr Gastroenterol Nutr. 2005; 41:S62-3.

40. Zhang SC, Bai YZ, Wang W, Wang WL. Stooling patterns and colonic motility after transanal one-stage pull-through operation for Hirschsprung's disease in children. J Pediatr Surg. 2005; 40:1766-72.

41. Lu C, Xie $\mathrm{H}$, Li $\mathrm{H}$, Geng $\mathrm{Q}$, Chen $\mathrm{H}$, Mo $\mathrm{X}$, et al. Feasibility and efficacy of home rectal irrigation in neonates and early infancy with Hirschsprung disease. Pediatr Surg Int [Internet]. 2019; 35:1245-53. Available from: https://doi.org/10.1007/s00383-019-04552-8.

42. Vũ PA, Thiện HH, Hiêp PN. Transanal one-stage endorectal pull-through for Hirschsprung disease: Experiences with 51 newborn patients. Pediatr Surg Int. 2010; 26:589-92.

43. Ekenze SO, Ngaikedi C, Obasi AA. Problems and outcome of Hirschsprung's disease presenting after 1 year of age in a developing country. World J Surg. 2011; 35:22-6.

44. Stensrud KJ, Emblem R, Bjornland K. Late diagnosis of Hirschsprung disease - Patient characteristics and results. J Pediatr Surg. [Internet]. 2012; 47:1874-9. Available from: https://doi.org/10.1016/j.jpedsurg. 2012.04.022. 